Article

\title{
Factors Affecting Inn Operators' Willingness to Pay Resource Protection Fees: A Case of Erhai Lake in China
}

\author{
Peng Li ${ }^{1}\left(\mathbb{D}\right.$, Ming-Hsiang Chen ${ }^{2,3,4, * \mathbb{D}}$, Ying Zou ${ }^{1}\left(\mathbb{D}\right.$, Mark Beattie $^{3}(\mathbb{D})$ and Linsi He ${ }^{5(\mathbb{C}}$ \\ 1 School of Business and Tourism Management, Yunnan University, Kunming 650091, China; \\ leap58@yahoo.com (P.L.); 18487254878@163.com (Y.Z.) \\ 2 Tourism and Social Administration College, Nanjing Xiaozhuang University, Nanjing 211171, China \\ 3 School of Hospitality Business Management, Carson College of Business, Washington State University, \\ Pullman, WA 99164-4742, USA; mabeattie@wsu.edu \\ 4 School of Business Administration, Anhui University of Finance and Economics, Bengbu 233030, China \\ 5 School of Community Resources and Development, Arizona State University, Phoenix, AZ 85004, USA; \\ hunanlynn@outlook.com \\ * Correspondence: ming-hsiang.chen@wsu.edu; Tel.: +1-509-335-2317
}

Received: 31 July 2018; Accepted: 1 November 2018; Published: 5 November 2018

check for updates

\begin{abstract}
Willingness to pay (WTP) is a foundation of payment for environmental services (PES) and varies according to different stakeholders. Because of its high-quality environment, numerous inns have appeared around Erhai Lake, which has become the inn sector leader in China. Declining water quality of the lake contrasts sharply with the increasing number of inns, thus a policy that balances economic development and water protection is needed desperately. The Erhai Lake Resource Protection Fee (ELRPF) is a form of PES, constructed on the basis of the contingent value method (CVM) involving the relationship between perceived benefits, institutional trust, awareness, and supportive attitude. Using relevant data obtained from a survey questionnaire, SmartPls 3.0 software was used to analyze the factors influencing inn operators' WTP. The results of the analysis of 307 questionnaires showed that institutional trust, PES cognition, and attitudes toward support significantly affected inn operators' WTP, while perceived benefit did not. This result differs from results of research on other tourism stakeholders. The reasons for this difference might be the specific identity of operators, their cultural and place identity, ability and professional education, and complexities of the broker of ecosystem services.
\end{abstract}

Keywords: inn operators; payment for ecosystem services (PES); Erhai Lake Resources Protection Fees (ELRPF); willingness to pay (WTP); broker of ecosystem services

\section{Introduction}

Payment for ecosystem services (PES, "E" in PES is environmental, ecological, or ecosystem—but the idea is the same. This concept is also called ecological compensation.) is a relatively new approach of sustainability, and there is not yet a settled definition of the term [1-3]. Pagiola et al. [1] think that PES is "mechanisms under which those who provide positive externalities are compensated for doing so, usually through payments from the beneficiaries". The views of scholars such as Wunder [2] define PES as "voluntary transactions between service users and service providers that are conditional on agreed rules of natural resource management for generating offsite service".

There is also a lot of literature [4,5] discussing the relationship between the Markets for Ecological or Environmental Services (MES) and PES. Markets for Ecological or Environmental Services refers to the market mechanism of environmental service transactions (e.g., polluting emission rights, water 
rights, fishing rights transactions, etc.), by "forcing" ecosystem services into the market model enabling individual environmental elements or nature resource types to be capitalized or financed. This market construction is highly selective and targets only economic efficiency. Payment for ecosystem services emphasizes the cooperation of market and non-market forces, and uses various payment mechanisms including taxation and subsidies including the market to achieve multiple objectives including ecological sustainability, fair distribution, and economic efficiency. Some scholars believe that PES differs from a narrow MES in that it opposes efficiency as a single goal [6,7].

In fact, both MES and PES are incentive ways to resolve the contradiction between environmental protection and economic development, but their focus is different. The essence of the PES mechanism is to transfer fees collected from beneficiaries of ecosystem services to providers who suffer economic losses when protecting the environment. There are different methods in different fields, such as forestry, water resource use, and mineral resource development. Tourism is an important area for the implementation of PES, and PES of tourism aims for a coordinated balance between industry development and environmental protection by incentives in tourism development [8].

For the flow of an ecological servicer to be sustainable, PES programs generally require secure sources of financing [1]. A stable balance must be maintained between buyers and providers of ecosystem services. The attitude and willingness of the buyer will inevitably affect the smooth operation of this policy mechanism. Willingness to pay (WTP) could be used to characterize their intentions and behavior in terms of PES $[9,10]$, but WTP results from a complex psychological process [11]. What influences ecosystem service buyers' WTP is whether managers have any control over the factors that influence WTP. Understanding payer WTP is important since stated preferences can help managers identify acceptable prices for non-market ecological services [12].

Willingness to pay generally is based on contingent valuation method (CVM) to build a hypothetical market and obtain preferences about environmental products, thus reflecting stakeholders' willingness to act. In 1963, Davis [13] evaluated the recreational value of the forest by CVM in Maine of the United States. After 2000, many researchers used CVM to study PES policies or standards for tourists and residents in some protected area against the background of tourism from the perspective of "beneficiary pays" [14-16]. Research related to willingness to pay has been a topic of considerable interest in the field of tourism.

At present, research on WTP for PES in tourism focuses mainly on three aspects: (1) Ways to realize PES based on WTP. This focuses on the approaches that payers (e.g., visitors and community residents) are recognized, and which kinds of methods that could gain more social support in different situations, for example ways to realize tourism PES based on WTP can include tickets [17,18], ecological taxes [19-21], usage fees [22,23], and protection fees [15]. (2) The amount of money for tourism PES is based on WTP. Because of the different compensation methods and targets, there are differences in the amount of money that compensation subjects are willing to pay [17,22,24,25]. (3) Factors influencing WTP for tourism PES. The WTP for tourism PES is influenced mainly by individual socio-economic characteristics (e.g., gender, income, education, age, etc.) and psychological factors (such as perceived benefits, institutional trust, environmental awareness, etc.) $[18,24,26,27]$. Tourists, operators, and community residents are the most important tourism non-organizational stakeholders [28]. Previous research on the factors affecting tourism PES based on WTP focused mainly on tourists and community residents. There are few studies on the factors influencing tourism operators, especially on the WTP of the operators from small and micro-enterprise, for example, inn operators. However, small-scale entrepreneurs are the main operators of tourism enterprises and the accommodation sector has been particularly emphasized in research related to small tourism firms [29]. As a kind of accommodation sector involving small-scale entrepreneurs, inns have developed rapidly in recent years in China. Inn operators include investors, decision makers, and managers of the inn.

Inns around Erhai Lake are excellent representations of the inn sector in China. The large number of inn operators located around the lake form a relatively unique troop. Rapid development of the inn sector around the lake has had a negative impact on its water quality. In November 2015, Dali 
municipal government put forth the "Erhai Lake Resource Protection Fee Proposal" (ELRPF) in order to make up funding gaps. Whether the ELRPF can be implemented smoothly depends largely on the willingness of the inn operators to pay for it. Thus, research on the factors influencing inn operators' WTP will have important scientific value and policy implications.

We developed the operators' hypotheses of WTP based on other tourism stakeholder's PES affecting factors, then from a questionnaire and face-to-face surveys. This paper uses partial least squares (PLS), an analytical technique for detecting or constructing predictive models, especially for causal model analysis between potential variables, which is superior to a general structural relationship model (LISREL). We obtained some valuable conclusions, which have implications for the policy design of PES for the open space and the operator subject who pursue multidimensional goals. The remainder of the paper is organized as follows: (1) It begins with a brief introduction to ELRPF and a literature review. (2) Hypotheses based on ELRPF and characteristics of inn operators are put forward and the structural model of WTP is constructed. (3) Survey data and methods are presented. (4) Findings on factors influencing inn operators' WTP are shown. (5) The paper ends with a discussion of policy implications and the final conclusions.

\section{Policy Background}

\subsection{Description of the Study Area}

Erhai Lake is located in Dali City, Yunnan Province, in the southwest of China (see Figure 1). With an area of $252.1 \mathrm{~km}^{2}$ and a circumference of $129.14 \mathrm{~km}$, it is a typical plateau lake [30]. The water quality of Erhai Lake, one of China's highly protected waters and an international tourism destination, has been a long-term focus for the domestic population. In the 1980s, because of the lake and other natural scenery, coupled with the unique traditional culture of the Bai indigenous people, Dali City became one of China's earliest international tourism destinations. The number of tourist arrivals grew from 4.29 million in 1998 to 9.60 million in 2015, an increase of $124 \%$. The number of overseas tourist arrivals increased from 54,000 in 1998 to 660,000 in 2015, an eleven-fold increase. Dali's proportion of total tourism revenue to GDP continued to grow, reaching 48\% in 2015 [31], and tourism has been the mainstay industry.

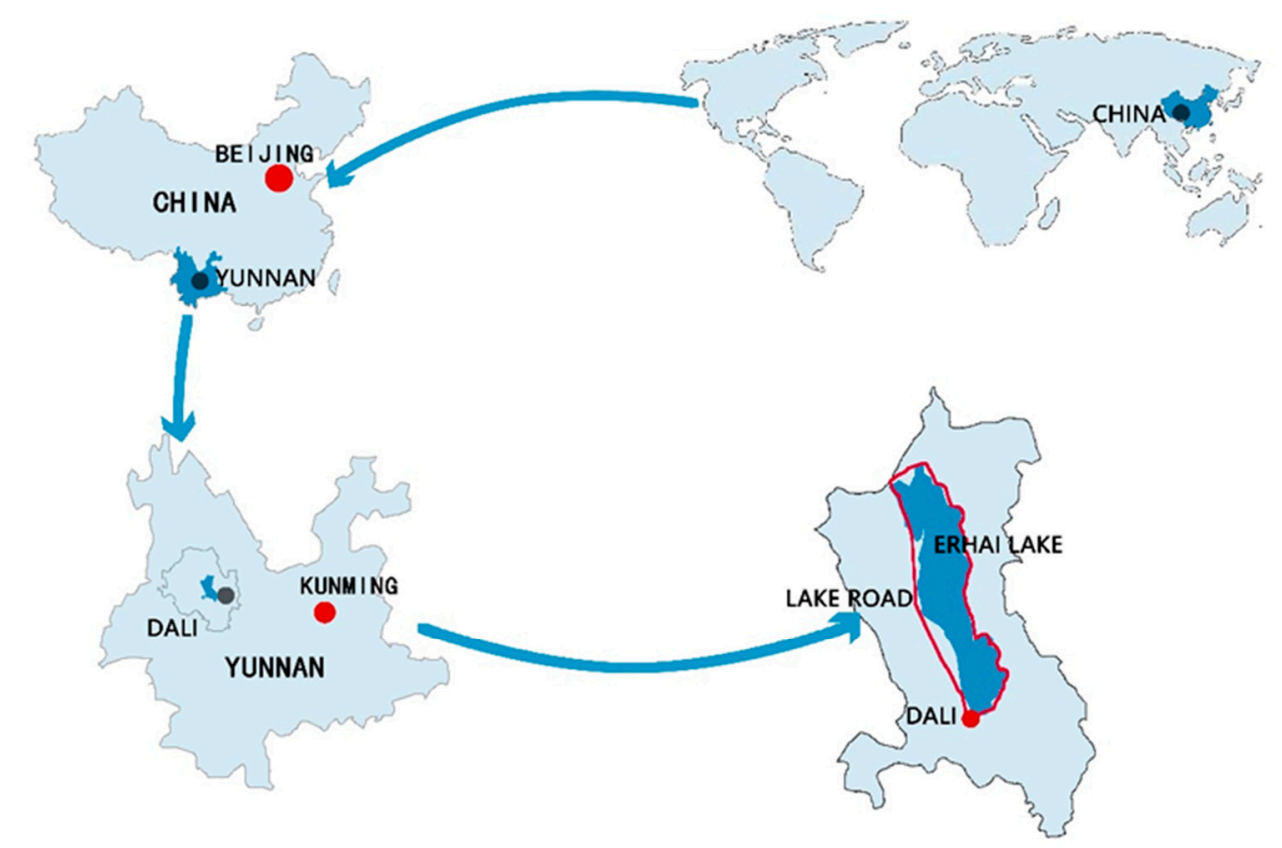

Figure 1. The location of Erhai Lake. 
The first inn at Erhai Lake, "Aisi Garden," opened in 1985. (In China, "Inn" as used herein refers to an accommodation resembling a homestay or Bed and Breakfast (B\&B), including not only private homes but also small luxurious hotels that provide overnight accommodations or vacations for tourists.) "Four Seasons Inn," the first approved inn by the Bureau of Industry and Commerce of Dali City, opened in April 1994 [32]. The construction of a scenic drive around the lake in 2008 provided opportunities for subsequent development of additional inns surrounding the lake. After 2010, people who came from Beijing and other megacities were fascinated by the natural scenery and environment in Dali. Many decided to live an idyllic life there free of heavy pressures. Southern Weekly, a famous newspaper in China, calls this phenomenon the "gold collar going back to the village" [33]. Many such people worked as homestay inn operators (hereinafter referred to as "operators").

Since 2010, the number of inns around Erhai Lake has grown rapidly, becoming a unique tourism attraction, greatly improving the popularity of Dali City and making the city a leader in the development of China's inn sector. The inns also promoted the development of Dali's tourism economy. The average room rate was $450 \mathrm{CNY}$ (equivalent 70 USD) per room per night, and there are more than 1500 inns around the lake. The total annual revenue generated is approximately 2 billion CNY. Tourism also stimulated local transportation, catering, shopping, and other consumption, increasing the total tourism revenue of Dali City significantly. The average annual revenue growth of tourism from 2010 to 2015 was $28.8 \%$ [31].

\subsection{Origin of the Erhai Lake Resource Protection Fee}

In 2014 Breakup Buddies was released, which is a famous Chinese romantic comedy and road film where the buddies cross a 3000-kilometre journey from Beijing to Dali City. There are many lake-view inn scenes in this movie, which attracted more tourists and investors.

According to some estimates, there were more than 1080 inns around the lake in December 2016 (Figure 2). Room rate income is the main source of gross income for the operators. This income is closely related to occupancy and room rates, which are not only affected by seasonality but also by the proximity to the lake. Especially in peak seasons, the average daily rate (ADR) is $1500 \mathrm{CNY}$, equivalent to the room price of a five-star hotel in a metropolis like Beijing or Shanghai. The price of a lake-view room is three to five times higher than one without, and the occupancy of these inns with lake-view rooms is also relatively higher. It has been shown that waterfront scenery has a great influence on prices and rent [34,35].

Because both natural (plateau lakes have longer water exchange periods) and human-caused factors (inflowing fresh water is reduced) influenced Erhai Lake's water quality. The water quality has been downgraded from Grades II-III in the 1990s to an overall Grade III in recent years. According to the national surface quality standard (GB/T14848-93), Grade I is pristine water sources (e.g., river headwaters and protected natural catchment areas), Grade V is limited agricultural water supply, inferior to Grade V is essentially useless. In 2015, the lake's water quality was Grade III, and the lake eutrophication index was 40.6, indicating that the water of Erhai Lake was shifting from Mesotrophic state to Eutrophic state. This is a comprehensive index, including five parameters such as Chla, divided into five levels of $0-100$ [36].

The pollution in Erhai Lake basin mainly comes from industry, urban and rural life, aquaculture, agricultural non-point source, service industry, soil erosion, dry and wet deposition, etc. Among them, livestock and poultry farming, rural life, and non-point source pollution sources are the main sources of pollution, and the three-kind pollution load discharged accounted for about $70 \%$ of the total load in 2014 [30]. Lack of sufficient sewage treatment facilities, the increased amount of sewage generated by the numerous inns, and the increased number of tourists, contributed to high levels of nutrients discharged into the lake, and this will threaten to lower water quality.

Recognizing the need to improve water quality, the government has put much effort into protecting the lake, which invested 2.824 billion CNY from 2011 to 2015, including a sewage treatment plant and pipe network construction, ecological restoration, and subsidizing farmers [30]. However, 
the outcome of this investment in water protection is not satisfactory and the lake's water quality is still declining. In April 2017, the Dali municipal government called for suspension of developing new inns around the lake until additional sewage treatment facilities are completed. It became clear that the government needed to propose solutions.

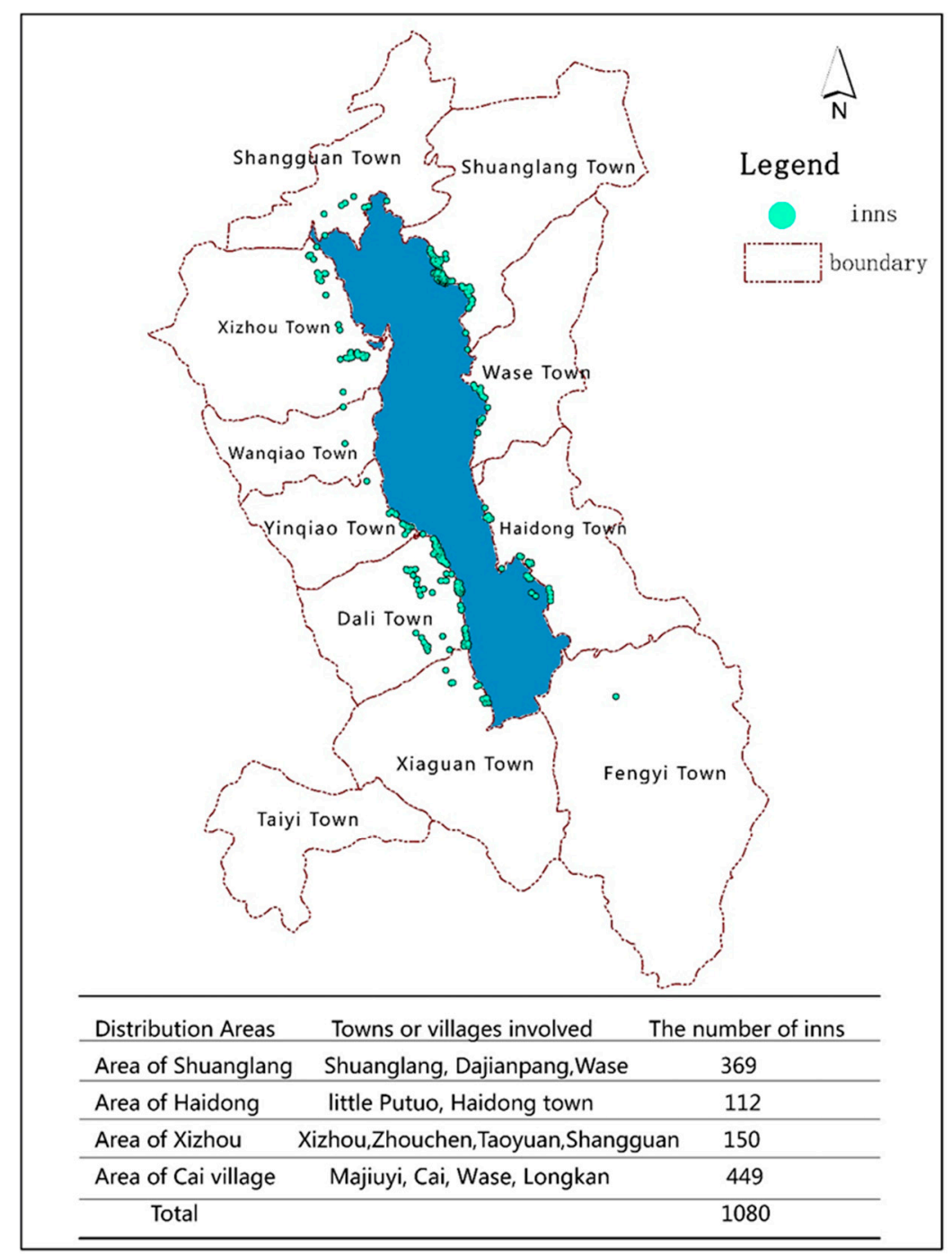

Figure 2. Distribution of inns registered online around Erhai Lake.

\subsection{Content of the Draft Proposal}

In November 2015, the Dali municipal government and the Price Control Administration of Yunnan Province submitted Proposals I and II, respectively seeking to rectify the environmental impact. After the different levels of government reached agreement, Proposal I was selected for trial. This paper focuses on Proposal I (hereinafter referred to as "the proposal"). The main aspect of Proposal I was to divide rooms into three grades according to the inn's distance from the lake and whether the room is situated on the lakeside. The three grades included: rooms within $100 \mathrm{~m}$ of the water with a lake view, rooms within $100 \mathrm{~m}$ of the water without a lake view, and rooms farther than $100 \mathrm{~m}$ from the lake. Proposal I included the following fees for each grade of room, respectively: 2000, 360, and 90 CNY per month. Proposal II stated that all inns must be charged ELRPF $2 \%$ of their income, regardless of the difference distance between the inn and the lake surface.

The ELRPF primarily monetizes Erhai Lake's ecosystem services through market mechanisms and motivates resource users to develop awareness of environmental conservation. According to the principle proposed by Pagiola and Wunder et al. [1-3], in the design policy system, the local 
residents are the providers of Erhai Lake's ecological services. For a long time, the local government has taken measures to protect Erhai Lake. The government has restricted dairy farming and heavily polluting crops, especially in the upstream and surrounding areas of lake. They asked farmers turn their farmland into wetlands, trying to reduce non-point source pollution. The operators are the buyers of Erhai Lake ecosystem services, as they resell the good environment and scenery of Erhai Lake to tourists, thus gaining more hedonic income. The local government is the manager of the policy system. They try to compensate the local residents from the operators' excess profits to make up the funding gap, then use the funds to reverse the deterioration of water quality.

\subsection{Controversy Around the Erhai Lake Resource Protection Fee}

Though these proposals were never officially announced, the papers were leaked to the public causing an uproar in China over the lack of transparency. The introduction of this proposal attracted attention from tourists, community residents, operators, news media, and other stakeholders. Operators, especially, responded negatively. Some media, such as the Beijing Youth Daily, referred to the ELRPF as an arbitrary charge with no legitimate basis [37]. Although the PES practices were implemented in 1998, China does not actually have a law regarding it. In addition, ELRPF is a fee that national tax reform required all pollution charges to be considered taxation. Since operators already pay garbage and sewage treatment fees, they viewed the ELRPF as an extra charge that goes beyond existing taxes.

At the same time, the responsibility for water pollution in Erhai Lake is difficult to define, because the existing sewage-monitoring is limited, it is difficult to measure the extent of lake pollution caused by inns. It made it difficult for operators to accept the requirements of the proposal.

\section{Literature Review and Development of Hypotheses}

\subsection{Literature Review}

Existing literature based on different compensation subjects studied psychological factors of PES based on WTP, focusing mainly on the following two aspects (Table 1), including (1) research on factors influencing tourists' PES based on WTP and (2) research on factors influencing local residents' PES based on WTP.

Research concerning influencing factors towards tourists' PES based on WTP including perceived interest, subjective norm, and perceived behavior control described in the following findings. Visitors' attitudes towards environmental protection may positively affect WTP; perhaps this is because visitors who care about the environment are more understanding of the rationale for a fee-paying policy, or they are simply willing to pay more for something they regard highly as shown by Reynisdottir et al. [18]. Environmental awareness might significantly influence visitors' WTP as described by Peters and Hawkins [38]. Received benefits and affective and functional links determine WTP intentions with regard to conservation and the loyalty of visitors in two suburban natural areas noted by López-Mosquera and Sánchez [27].

Factors influencing tourists' WTP are related to their previous pro-environmental activities claimed Halkos and Matsiori [39]; whether or not respondents had previously participated in an environmental protection plan by paying part of the cost was the most important decisive parameter for WTP. Individuals with positive attitudes and strong moral norms show higher WTP for the conservation of an urban park indicated López-Mosquera et al. [40]. An individual's attitude, subject norm, and perceived behavioral control are significant factors that can influence a visitor's WTP when visiting public parks as shown by Huang et al. [41]. About $86 \%$ of respondents were willing to pay to ensure better management noted by Kaffashi et al. [42]. The higher the respondents' satisfaction from their visit experience, the higher their WTP. 
Table 1. Psychological factors on willingness to pay for ecosystem services based on towards tourists and residents representing a literature review.

\begin{tabular}{|c|c|c|}
\hline Subject & Psychological Factors & Literature \\
\hline \multirow{3}{*}{ Tourist } & Perceived benefit & $\begin{array}{l}\text { López-Mosquera and Sánchez (2013) [27]; } \\
\text { Kaffashi et al. (2015) [42] }\end{array}$ \\
\hline & $\begin{array}{l}\text { Environmental } \\
\text { awareness and } \\
\text { knowledge }\end{array}$ & $\begin{array}{l}\text { Halkos and Matsiori (2014) [39]; } \\
\text { Peters and Hawkins (2009) [38] }\end{array}$ \\
\hline & $\begin{array}{c}\text { Environmental } \\
\text { protection Attitude }\end{array}$ & $\begin{array}{l}\text { López-Mosquera, García and Barrena (2014) [27]; } \\
\text { Huang, et al. (2014) [41]; Reynisdottir, et al. (2008) [18] }\end{array}$ \\
\hline \multirow{3}{*}{ Residents } & Perceived benefit & $\begin{array}{l}\text { Hayes et al. (2015) [44]; Salazar and García Menéndez } \\
\text { (2007) [43]; Lo and Jim (2010) [45] }\end{array}$ \\
\hline & $\begin{array}{l}\text { Social trust and } \\
\text { institutional trust }\end{array}$ & Song, Lv and Li (2015) [46]; Halkos and Jones (2012) [39] \\
\hline & $\begin{array}{l}\text { Environmental } \\
\text { protection Attitude }\end{array}$ & Rodríguez-Ortega, et al. (2016) [47] \\
\hline
\end{tabular}

Second, the factors influencing local residents' PES based on WTP are mostly the same as the factors influencing that of tourists, including perceived benefits, and support attitudes. However, the impact of satisfaction and other factors on local residents' WTP is not significant. Salazar and García Menéndez [43] conducted a contingent valuation survey of 900 randomly chosen inhabitants; results showed that WTP is considerably higher for people who live closer to a planned park because it is more accessible to them. The study of Hayes et al. [44] showed that the perception of benefits of tourism, usually in the form of economic benefits, can positively affect attitudes towards conservation.

Lo and Jim [45] suggested that residents' intention to pay is based more on pragmatic needs than on moral or altruistic reasons. The dominant motive for improving air quality reflects general anxiety about chronic health-threatening problems. Song et al. [46] indicated that $81.4 \%$ of respondents were willing to pay for the conservation of urban green spaces, and trust in the government was the most important factor that led to a high protect willing. Halkos and Jones [39] suggested that social trust positively affects WTP an entrance fee and a community tax (market-based and community-based scenario, respectively). Rodríguez-Ortega et al. [47] examined how psychographic profiles affect WTP for ecosystem services in Mediterranean high-nature value farmland; they found that attitudes concerning ecosystem services strongly influence their WTP.

In summary, whether involving tourists or local residents, psychological factors affecting WTP for PES are mainly perceived benefits [44,48,49], social trust and institutional trust [39], environmental awareness and knowledge [38,50,51], and environmental protection attitude [18].

Characteristics of tourism small operators involve multiple identities, such as those of tourists, residents, and business owners. Previous studies pay more attention to the first two roles' WTP on PES. The inn operators are fusion of diversity between residents and tourists, and they have dual attributes of production and life in business process [52]. Therefore, we assume that the main psychological factors that affects both the residents and visitors' WTP on PES are adapt to the inn operators.

\subsection{Development of Hypotheses}

Based on extant research on tourists and local residents on their WTP, an influencing factor new model for inn operators' WTP for PES has been constructed. The independent variables in the model, perceived benefits, institutional trust, PES cognition, and support attitude were chosen as the major factors influencing inn operators' WTP, verified in previous documents.

\subsubsection{Perceived Benefit}

Perceived benefits are subjective feelings and evaluations of the subject toward purchasing a product or service [53], including utilitarian benefits and symbolic benefits [54]. Numerous studies 
showed that consumer's perceived benefits significantly influenced their WTP compensation $[55,56]$. López-Mosquera and Sánchez et al. [48] found that the perceived benefit of tourists and residents is an important factor affecting the WTP for PES. Tourists and community residents received different perceived benefits from ecosystem services, and tourists obtain tourism experiences at destinations, and residents enjoy recreational opportunities, although they may not be aware of the importance of ecosystem services to this public land. But they are willing to pay for PES.

Inn operators obtain more perceived benefits than tourists and local residents. They receive substantial benefits (such as operating income and enjoyment of a good environment) as well as symbolic benefits from Erhai Lake; these latter benefits include enjoying the social and psychological benefits brought about by the large number of inn operators gathered around Erhai Lake. Moreover, ELRPF is supplemental to environmental protection investment and farmers' subsidies, and high water quality can be maintained for the long term, then operators can gain more perceived benefits, including hedonic income and environmental enjoyment. Based on presented research and these operator's situation, the following hypothesis was formulated (H1):

Hypothesis 1 (H1). Inn operator's perceived benefit has a significant positive impact on their WTP.

\subsubsection{Institutional Trust}

In many cases, PES requires specialized agencies to formulate policies as well as collection and use of funds. Trust in institutions refers to the level of trust that people have in certain institutions connected with environmental management issues [57]. Institutional trust was examined in relation to the good that was being valued [58]. A high level of institutional trust produces a positive impact on the acceptance of environmental policy and facilitation of pro-environmental behavior [59]. In the case of environmental public goods, institutional trust is expected to significantly affect WTP [39,60]. The more trust tourists and residents have in environmental management institutions, the more likely they are to pay PES fees [61].

Because the proposal is enacted by the local government, the main policy makers and fund management managers of the organization will be members of the Dali municipal government. The more trust inn operators have in the Dali municipal government, the more likely they are to pay the ELRPF. In light of the preceding considerations, we posit the following hypothesis (H2):

Hypothesis 2 (H2). Inn operator's institutional trust has a significant positive impact on their WTP.

\subsubsection{Cognition of PES}

Cognition of PES (PESC) is the PES awareness and knowledge of the relevant subject. Payment for ecosystem services cognition not only includes the understanding of the principle of PES [62], but also the cognition of PES policy. Empirical research shows that consumer's PES cognition is significantly positively related to their WTP [19,62,63], among which Kostakis and Sardianou et al. [63] found that the more PES cognition tourists and residents have, the more willing they are to pay PES fees.

The ELRPF is a form of PES, but few inn operators recognize this. Only the inn operators with a high understanding of PES understand the principles, roles, and mechanisms of the ELRPF, and this understanding will, to a certain extent, stimulate the inn operators to pay ELRPF. Thus, based on extant research, the following hypothesis is formulated (H3):

Hypothesis 3 (H3). Inn operator's PES cognition has a significant positive impact on their WTP.

\subsubsection{Support Attitude}

Attitude refers to the establishment of values, beliefs, and summary of personal evaluation of specific things [64]. In the contingent valuation model for PES, support attitude has always been 
considered to have a significant impact on WTP $[47,65,66]$. Support attitude towards PES policy from tourists and local residents significantly influences their WTP.

The attitude of inn operators for ELRPF is undoubtedly an important basis for the smooth implementation of the policy. If the inn operators object to or are less supportive of the policy, it will be difficult to collect the ELRPF. Based on previous studies, it was hypothesized that (H4):

Hypothesis 4 (H4). Inn operator's support attitude has a significant positive impact on their WTP.

Willingness to pay on PES is a measurable variable. Based on previous research, the logical model assumptions that reflect the causal relationship between potential variables was established (Figure 3).

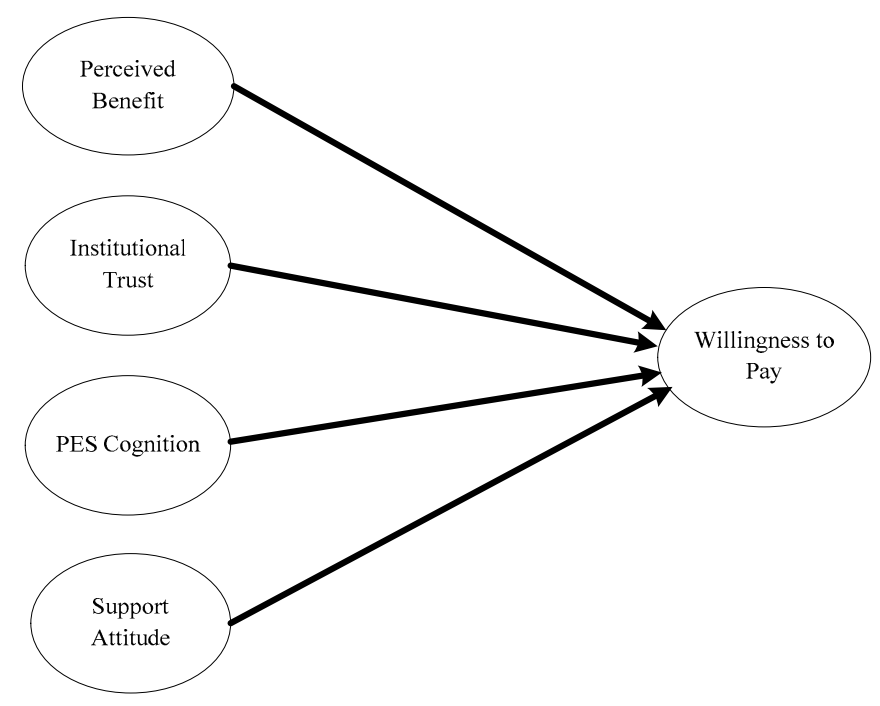

Figure 3. Research hypotheses.

\section{Data and Methodology}

\subsection{Data Collection}

There were two kinds of data sources. The first, statistical data, mainly including the number of tourists, tourism income, and environmental data; these data were obtained mainly from the Dali government official website and newspapers. The other source of data, survey data, was mainly questionnaires, through on-site investigations conducted with operators, and in-depth interviews with local government officials, scholars, and leaders of inn associations.

In addition to the latent variable of WTP, the remaining four variables included perceived benefits, institutional trust, cognition of PES, and support attitudes; all containing multiple observational variables (shown in Table 2). The latent variable perceived benefits can be transformed further into observational variables including increased income, dreamed lifestyle, natural environmental benefits [67,68], and business motivation [69]. The latent variable institutional trust mainly considered Dali municipal government directly related to ELRPF and the inn operators, and the attitude of inn operators to the Dali government. The latent variable PES cognition included the understanding of the principles, characteristics of PES and the cognition of ELRPF policy, and inn operators' responsibilities. The support attitude is measured mainly on the degree of support from the inn operators for PES policies and resource protection fees [70,71].

After the latent variables were determined, the questionnaire for operators was designed. This questionnaire was divided into three sections: (1) the socio-demographic characteristics and views on room rates associated with a lake view; (2) factors that may influence the WTP a resource protection fee; (3) reasons for being unwilling to pay the resource fee. Other than WTP, all other latent variables include multiple measured variables (Table 2). The main part of the questionnaire 
used a 5-point Likert-type scale for assessment where 1 represents "strongly agree," and 5 represents "strongly disagree."

Table 2. Questionnaire items used in the main survey.

\begin{tabular}{ll}
\hline Latent Variables & Descriptions \\
\hline & PB1: I love the lifestyle as an inn operator at Erhai Lake. \\
& PB2: My personal income is increasing at Erhai lake. \\
Perceived Benefit (PB) & PB3: I enjoy the local natural environment and ecosystem service. \\
& PB4: I meet more interesting people at Erhai Lake. \\
\hline \multirow{2}{*}{ Institutional Trust (IT) } & IT1: The local government is trustworthy. \\
& IT2: The government is fair to local and foreign operators. \\
\hline & PESC1: A beneficiary should bear the responsibility of PES. \\
PES Cognition (PESC) & PESC2: The PES of operators should match their derived benefits. \\
& PESC3: The ELRPF is a kind of PES. \\
& PESC4: The ELRPF is reasonable. \\
\hline \multirow{2}{*}{ Support Attitude (SA) } & SA1: I support PES promotion at Erhai Lake. \\
& SA2: I support ELRPF.
\end{tabular}

Two pre-tests were performed in succession to develop the questionnaire. The first pre-test was in the form of electronic questionnaires through the "Questionnaire Star" platform by WeChat from which 57 questionnaires were collected. The second pre-test was carried out face-to-face, from which 70 questionnaires were collected. The survey was checked in terms of comprehensibility, overlapping content, and completeness of content.

Based on the final questionnaire, operators were surveyed face-to-face using a combination of questionnaires and interviews. Stratified sampling and random sampling were used to select the sample, which included areas close to the lake, such as Shuanglang, as well as districts relatively far from the lake, such as Dali Old City. Sampling continued over 20 days from July to August 2016. A total of 320 questionnaires were collected, 13 of which proved invalid, leaving 307 valid questionnaires that were used for hypotheses testing. Information collected about the operators included socio-demographic and operational characteristics (see Tables 3 and 4).

\subsection{Analysis Method}

Variance-based SEM (structural equation model) was employed using partial least squares (PLS) to test hypotheses and explain the relationships, where WTP is the dependent variable and latent variables are perceived benefits, etc. [72]. SmartPLS (version 3.0) was selected as the calculation software with the path-weighting scheme selected as the weighting scheme, the maximum number of iterations set at 1000, and the iteration stop threshold set at 10-7 [73].

Partial least squares has advantages over traditional SEM. Partial least squares is commonly used when hypotheses are not established based on a well-elaborated theoretical framework but are the result of an exploratory study design. Partial least squares works well for small sample sizes [74], and can handle non-normal distributions relatively well. Furthermore, PLS is often used in situations to identify relationships among latent variables [55].

After analyzing the research data using the PLS method through SmartPLS3.0, the validity and reliability of the measurement model needs to be assessed. Once the validity and reliability of the measurement model has reached a satisfactory level, the structural model used to explain the relationships between variables can be persuasive [75]. 
Table 3. Demographic profile of respondents.

\begin{tabular}{llllll}
\hline Items & Characteristics & Proportion & Items & Characteristics & Proportion \\
\hline \multirow{2}{*}{ Gender } & Male & $57.3 \%$ & & Dali & $39.7 \%$ \\
& Female & $42.7 \%$ & & Yunnan Province except for Dali & $7.8 \%$ \\
Marital & Single & $40.0 \%$ & Native place & Eastern provinces & $14.7 \%$ \\
status & Married & $59.0 \%$ & & Western Provinces & $14.7 \%$ \\
& Divorced & $1.0 \%$ & & Central provinces & $16.3 \%$ \\
& $18-24$ & $20.8 \%$ & & Northeastern provinces & $6.8 \%$ \\
Age & $25-44$ & $65.2 \%$ & & Less than high school & $14.0 \%$ \\
& $44-64$ & $11.7 \%$ & Education & High school & $45.6 \%$ \\
& $>65$ & $2.3 \%$ & & Bachelor & $37.8 \%$ \\
& & & & Graduate & $2.6 \%$ \\
\hline
\end{tabular}

Table 4. Inn Characteristics.

\begin{tabular}{|c|c|c|c|c|c|}
\hline Items & Characteristics & Proportion & Items & Characteristics & Proportion \\
\hline \multirow{4}{*}{ Business mode } & Individual & $63.2 \%$ & \multirow{5}{*}{$\begin{array}{l}\text { Average occupancy } \\
\text { (low season) }\end{array}$} & $20-30 \%$ & $21.8 \%$ \\
\hline & Joint & $27.7 \%$ & & $30-40 \%$ & $18.6 \%$ \\
\hline & Lease & $9.1 \%$ & & $40-50 \%$ & $12.7 \%$ \\
\hline & $<1$ & $10.4 \%$ & & $50-60 \%$ & $16.9 \%$ \\
\hline \multirow{4}{*}{ Age } & $1-3$ & $38.1 \%$ & & $>60 \%$ & $13.4 \%$ \\
\hline & $3-5$ & $20.3 \%$ & \multirow{6}{*}{$\begin{array}{l}\text { Average price } \\
\text { (Peak season) }\end{array}$} & $<200$ & $18.6 \%$ \\
\hline & $5-10$ & $10.7 \%$ & & $200-400$ & $40.1 \%$ \\
\hline & $>10$ & $20.5 \%$ & & $400-600$ & $22.1 \%$ \\
\hline \multirow{5}{*}{$\begin{array}{l}\text { Number of guest } \\
\text { rooms }\end{array}$} & $<5$ & $3.6 \%$ & & $600-800$ & $9.4 \%$ \\
\hline & $5-10$ & $44.3 \%$ & & 800-1000 & $4.9 \%$ \\
\hline & $11-15$ & $28.7 \%$ & & $>1000$ & $4.9 \%$ \\
\hline & $16-20$ & $15.0 \%$ & \multirow{6}{*}{$\begin{array}{l}\text { Average price } \\
\text { (Low season) }\end{array}$} & $<100$ & $17.6 \%$ \\
\hline & $>20$ & $8.4 \%$ & & $100-200$ & $26.4 \%$ \\
\hline \multirow{9}{*}{$\begin{array}{l}\text { Average occupancy } \\
\text { (Peak season) }\end{array}$} & $<40 \%$ & $5.9 \%$ & & $200-300$ & $24.8 \%$ \\
\hline & $40-50 \%$ & $5.2 \%$ & & $300-400$ & $15.0 \%$ \\
\hline & $50-60 \%$ & $9.1 \%$ & & $400-500$ & $6.5 \%$ \\
\hline & $60-70 \%$ & $13.0 \%$ & & $>500$ & $9.7 \%$ \\
\hline & $70-80 \%$ & $20.8 \%$ & \multirow{5}{*}{$\begin{array}{l}\text { Distance from water } \\
\text { surface }\end{array}$} & $<50$ & $53.5 \%$ \\
\hline & $80-90 \%$ & $30.0 \%$ & & 50-100 & $14.0 \%$ \\
\hline & $>90 \%$ & $16.0 \%$ & & $100-150$ & $7.5 \%$ \\
\hline & $<10 \%$ & $4.9 \%$ & & 150-200 & $5.5 \%$ \\
\hline & $10-20 \%$ & $11.7 \%$ & & $>200$ & $19.5 \%$ \\
\hline
\end{tabular}

\section{Results}

\subsection{Measurement Model}

The values of indicator loading, Cronbach Alpha, combined reliability (CR), average variance extracted (AVE), and discriminant validity were used to examine the reliability and validity of the measurement model. According to the research results of Hair et al. [74], the PLS algorithm is used to obtain internal consistency reliability (CR should be higher than 0.70 ), indicator reliability (indicator loadings should be higher than 0.70), and convergent validity (AVE should be higher than 0.50). Discriminant validity is assessed according to criteria established by Fornell and Larcker [75], Chin [76], and Henseler et al. [77].

As shown in Table 5, all values of indicator loadings, except for that of CE1, were above 0.700, indicating good reliability. Cronbach's alpha values were greater than or equal to 0.754 , and composite reliability values were greater than or equal to 0.842 , indicating that all constructs exhibit high levels of internal consistency reliability. In addition, the AVE values were well above the minimum required level of 0.50 , and thus demonstrated that all constructs had convergent validity. To assess discriminant validity, we examined the Fornell-Larcker criterion for cross-loadings and the Heterotrait-Monotrait ratio of correlations (HTMT). Fornell and Larcker state that a way to indicate discriminant validity is to take the square root of the AVE value and determine whether it is larger than the correlations [73]. In this study, the square root of each AVE is larger than the correlations, which meets the Larcker and Fornell criterion (Table 6). 
Table 5. Reliability and validity of variables.

\begin{tabular}{cccccc}
\hline Construct & Item & Loading & Cronbach's Alpha & CR & AVE \\
\hline Perceived benefit (PB) & PB1-PB4 & $0.738-0.796$ & 0.754 & 0.844 & 0.575 \\
Institutional trust (IT) & IT1-IT2 & $0.965-0.966$ & 0.928 & 0.965 & 0.932 \\
PES cognition (PESC) & PESC1-PESC4 & $0.686-0.811$ & 0.755 & 0.842 & 0.572 \\
Support attitude (SA) & SA1-SA2 & $0.926-0.946$ & 0.859 & 0.934 & 0.876 \\
Willingness to pay (WTP) & WTP1 & 1 & 1 & 1 & 1 \\
\hline
\end{tabular}

Table 6. Discriminate validity.

\begin{tabular}{cccccc}
\hline Construct & PB & IT & PESC & SA & WTP \\
\hline PB & 0.758 & & & & \\
IT & 0.392 & 0.966 & & & \\
PESC & 0.509 & 0.463 & 0.756 & & \\
SA & 0.414 & 0.456 & 0.669 & 0.936 & \\
WTP & 0.475 & 0.522 & 0.680 & 0.657 & 1.000 \\
\hline
\end{tabular}

Note: The diagonals represent the square root of AVE and the off-diagonals represent the correlation.

Furthermore, another method for using cross-loadings to assess discriminant validity is to calculate the correlations between latent variables and other indicators beside its own block. The indicator loading of its respective latent variable should be higher than the indicator loading crossed with other latent variables [75]. As shown in Table 7, an indicator loading on its own construct is higher than its cross-loadings with other constructs, which meets Chin's criteria. Henseler et al. believe that the new approach, HTMT, shows superior performance over the traditional Fornell-Larcker criterion, and they suggest that the standard to examine discriminant validity should be less than $0.85[77,78]$.

Table 7. Cross loading.

\begin{tabular}{cccccc}
\hline Construct & PB & IT & PESC & SA & WTP \\
\hline PB1 & 0.753 & 0.255 & 0.382 & 0.255 & 0.384 \\
PB2 & 0.796 & 0.313 & 0.379 & 0.328 & 0.363 \\
PB3 & 0.738 & 0.367 & 0.422 & 0.375 & 0.382 \\
PB4 & 0.743 & 0.236 & 0.351 & 0.285 & 0.303 \\
IT1 & 0.378 & 0.965 & 0.438 & 0.451 & 0.492 \\
IT2 & 0.379 & 0.966 & 0.456 & 0.429 & 0.517 \\
PESC1 & 0.459 & 0.276 & 0.686 & 0.399 & 0.388 \\
PESC2 & 0.427 & 0.376 & 0.752 & 0.400 & 0.468 \\
PESC3 & 0.323 & 0.274 & 0.771 & 0.585 & 0.507 \\
PESC4 & 0.373 & 0.456 & 0.811 & 0.593 & 0.648 \\
SA1 & 0.393 & 0.389 & 0.570 & 0.926 & 0.571 \\
SA2 & 0.384 & 0.459 & 0.675 & 0.946 & 0.654 \\
WTP & 0.475 & 0.522 & 0.682 & 0.657 & 1.000 \\
\hline
\end{tabular}

The present study also used HTMT criterion, and the results range from 0.448 to 0.805 , meeting the criteria of Henseler et al. [77] (see Table 8). Summarizing the test results above, the measurement model in this research has sufficient reliability and validity, and can provide enough support for the structural model to test the hypotheses. 
Table 8. Heterotrait-Monotrait (HTMT) ratio.

\begin{tabular}{cccccc}
\hline Construct & PB & IT & PESC & SA & WTP \\
\hline PB & 1.000 & & & & \\
IT & 0.461 & 1.000 & & & \\
PESC & 0.686 & 0.543 & 1.000 & & \\
SA & 0.510 & 0.508 & 0.803 & 1.000 & \\
WTP & 0.544 & 0.542 & 0.762 & 0.706 & 1.000 \\
\hline
\end{tabular}

\subsection{Structural Model}

Once the construct measures were confirmed as reliable and valid, we proceeded to assess the structural model. The primary criterion for assessing a structural model is to determine the coefficients of endogenous latent variables $\left(R^{2}\right)$ [79], which indicate the variance share of the endogenous ultimate criterion explained by the other model variables. $R^{2}$ values of at least $0.19,0.33$, and 0.67 were qualified as weak, moderate, and strong, respectively [76]. In our research, the $\mathrm{R}^{2}$ value for WTP was 0.614, which shows that the model had strong explanatory ability.

We then performed bootstrapping (5000 resample) to assess the significance of path coefficients in the structural model [80]. By evaluating the path coefficient, we can know the strength of the relationship between the latent variables, and at least 0.1 should be achieved to qualify as a meaningful path [81]. Perceived benefit had a positive impact on WTP, with a path coefficient of 0.081 . However, the impact was not significant, as it does not reach the lower limit of 0.1 , which makes H1 invalid. The path coefficient for institutional trust was 0.194 , exceeding 0.1 , which reveals that it has a positive and significant impact on WTP, and thus, H2 is supported. The effect of PES cognition on WTP was the greatest, as the path coefficient is 0.398 , well above the significance level of 0.1 , which supports H3. Support attitude also had a positive impact on WTP, with a path coefficient of 0.287 , which also surpassed the significance level of 0.1 , and thus supports H4 (Figure 4).

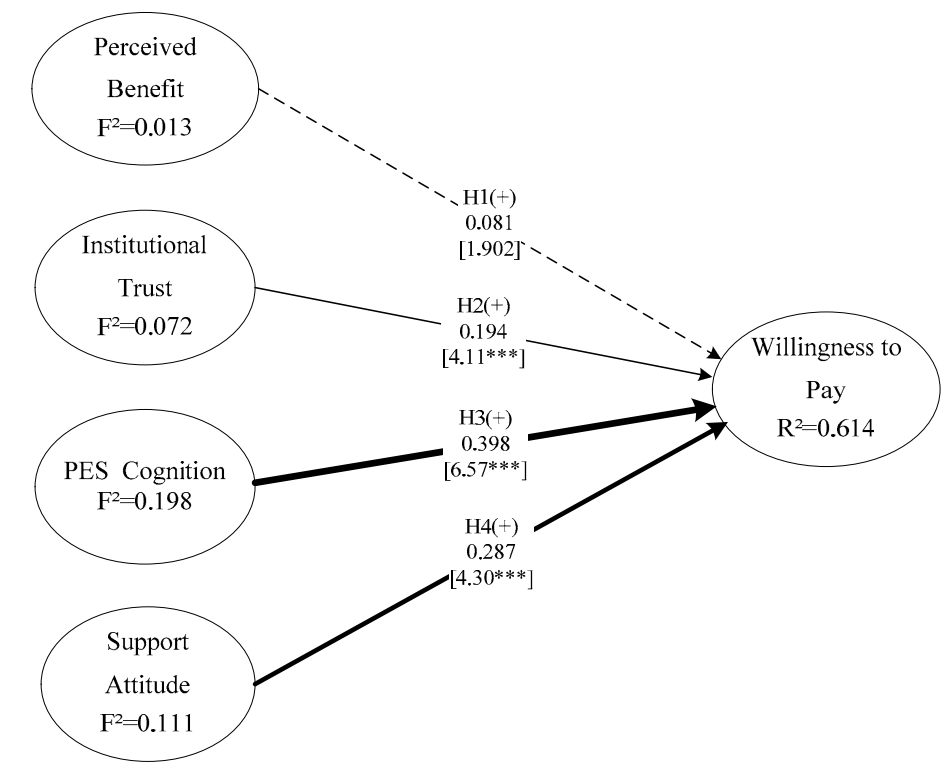

Figure 4. Results of structural modeling analysis. (Standardized path coefficients are reported. $* * * p<0.001)$.

In the structural model, the $\mathrm{R}^{2}$ value was not the only important factor. The $\mathrm{f}^{2}$ value, should also be examined. An $\mathrm{f}^{2}$ value of at least $0.02,0.15$, and 0.35 represent small, medium, and large effects, respectively [75]. Perceived benefit had the least effect on WTP $\left(f^{2}=0.013\right)$, and PES has a moderate effect on WTP $\left(f^{2}=0.198\right)$ (Figure 3 ). Using the blindfolding method to obtain the predictive relevance $\left(\mathrm{Q}^{2}\right)$, combined with a resulting $\mathrm{Q}^{2}$ value larger than zero, indicated that the path model 
had predictive relevance. In this research, the $\mathrm{Q}^{2}$ value for WTP was 0.558 , providing support for the model's predictive relevance.

\subsection{Demographic Characteristics}

A difference test was conducted using the independent sample $t$-test and the one-way ANOVA to analyze whether the five demographic variables, gender, marital status, age, birth, and education, were significantly different in WTP. Since there were only two independent groups in the internal groups of "gender" and "household registration" variables, independent sample $t$-test was used to conduct the difference test (Table 9); for the remaining three variables, "marriage," "age" and "education," one-way ANOVA was used for differential testing (Table 10).

Table 9. Independent-Samples $t$-test towards different groups of people.

\begin{tabular}{cccccc}
\hline \multirow{2}{*}{ Demographic Factors } & \multicolumn{3}{c}{ Levene Test } & \multicolumn{3}{c}{ Equivalence of the Average $\boldsymbol{t}$-Test } \\
\cline { 2 - 6 } & $\mathbf{F}$ & Significance & $\mathbf{T}$ & Df & Sig \\
\hline Gender & 0.108 & 0.742 & 0.173 & 305 & 0.863 \\
Household registration & 0.596 & 0.441 & -3.669 & 306 & 0.000 \\
\hline
\end{tabular}

Table 10. ANOVA analysis of willingness to pay for different groups of variances.

\begin{tabular}{cccccccc}
\hline $\begin{array}{c}\text { Demographic } \\
\text { Factors }\end{array}$ & $\begin{array}{c}\text { Sum of Squares } \\
\text { between Groups }\end{array}$ & $\begin{array}{c}\text { Degree of Freedom } \\
\text { between Groups }\end{array}$ & $\begin{array}{c}\text { Sum of Squares } \\
\text { within Groups }\end{array}$ & $\begin{array}{c}\text { Degree of Freedom } \\
\text { within Groups }\end{array}$ & $\begin{array}{c}\text { Mean } \\
\text { Square }\end{array}$ & F & Sig \\
\hline Marriage status & 6.581 & 2 & 279.868 & 304 & 3.291 & 3.574 & 0.029 \\
Age & 6.133 & 3 & 280.316 & 303 & 2.044 & 2.210 & 0.087 \\
Education & 14.652 & 3 & 271.797 & 303 & 4.884 & 5.445 & 0.001 \\
\hline
\end{tabular}

From Table 10, for the "gender" variable, we know that under the condition of the established homogeneity of variance test, the value of $t$ is 0.173 and the value of $p$ is 0.863 which is much higher than 0.05 , indicating that there is no significant difference in the "willingness to pay" between different "gender" groups. And for the "Household registration" variable, the value of $t$ is -3.669 and the value of $p$ is 0.000 which is much lower than 0.05 , indicating that there is significant difference in the "WTP" for people from different places. For the "age" variable, the significance value of the "age" factor is greater than 0.05 , indicating that the dependent variable, WTP, does not have a significant difference in the "age" factor. And for the "marital status" and "education" variable, the value of both $p$ is lower than 0.05 , indicating that WTP has significant difference in the "marital status" and "education" factor. In order to understand more completely the specific differences between the two internal groups of the "marital status" and "education" factors that exhibited significant differences, multiple comparisons of LSD were performed.

By comparison, the result showed that the "WTP" dependent variable only differs significantly between divorced and non-divorced groups, but the sample size of divorcees is too small (three people), which cannot objectively reflect the divorce group's actual WTP; thus the "marital status" factor's differential performance should not be considered. The WTP dependent variable is significantly different between undergraduate, graduate and below undergraduate (between junior college and grade school).

Combining the results from the data analysis in Table 11, we ultimately obtained the differences between the two factors of "province" and "education" in the dependent variable "WTP." People who are from Dali, Yunnan province were more reluctant to pay while the people with higher education levels tended to be more willing to pay. 
Table 11. Descriptive statistics of willingness to pay for different groups.

\begin{tabular}{ccccc}
\hline Demographic Factors & Groups & Numbers & Average & Standard Deviation \\
\hline \multirow{2}{*}{ Household registration } & People from Dali City & 122 & 2.7131 & 0.85744 \\
& People from Dali City outside & 185 & 3.1189 & 1.00375 \\
& Less than high school & 43 & 2.8372 & 0.89789 \\
& High school & 140 & 2.7643 & 0.84488 \\
Education & Bachelor & 116 & 3.2328 & 1.08233 \\
& Graduate & 8 & 3.0000 & 0.75593 \\
& Sum & 307 & 2.9577 & 0.96753 \\
\hline
\end{tabular}

\section{Discussion and Implications}

\subsection{Discussion}

The research results showed that institutional trust, PES cognition and support attitude significantly affect WTP, a finding in agreement with previous results. However, the inn operators' perceived benefit showed no significant impact on their WTP, in contrast to previous studies. Thus, we discuss this significant finding in the following three points: (1) cultural and place identity, (2) operators' ability, and (3) professional education.

(1) The operators have not strong cultural identity with Bai indigenous people. The PES fees paid by tourists are mainly intended to limit the impact of environment damage on hedonic interests, but the inn operators are no longer tourists. During the early years, many tourists travelled to Dali before they become inn operators. Most of them rented a local farmhouse and decorated their inn, resulting in an intimate, quaint, and attractive house with a relaxing home-away-from-home atmosphere [81]. Cultural identity influences their lifestyle and action, because they like the lifestyle of the Bai indigenous people residents and agree with the Bai culture around Erhai Lake. Their inns tend to be lifestyle-oriented toward those who prefer to enjoy an idyllic life for long time.

After 2014 more and more people begin to invest in inns to make a profit, who are no longer the gold collars from Beijing and Shanghai, but small investors from many below average cities. The regional distribution of the operators could explain this, the main proportion of operators from outside eastern of Yunnan, including western, central, northeastern provinces (the numbers of provinces in each region is $11,6,13$, and 4 ) is $14.7 \%, 14.7 \%, 16.3 \%$ and $6.8 \%$. But Beijing, Shanghai, Guangzhou and Shenzhen all megacities are located in the eastern province. For the inn operator, from the lifestyle of a few people had become a way of livelihood. Many people were moving in Erhai Lake area not in order to live pastorally, but to speculate on rising room rates in the short term. Profit-oriented operators tend to be a significant proportion of operators and they are reluctant to pay for ecosystem services.

The operators were short of place attachment in Erhai Lake and Dali city. In other studies, local community members are willing to pay for ecosystem services because of their local identity and attachment [82]. More than $60 \%$ of the inn operators are from outside Yunnan province, and the proportion of investors outside Yunnan province is even higher, exceeding $90 \%$. Few of them consider themselves to be part of the local community.

With a low sense of local identity and place attachment, they were described as the residential guest— "New Dali people" — an intermediary between the host and the guest [52]. The gap between the "New Dali people" and "Old Dali people" is too wide, two kinds people are too hard to weld into a community. For example, schools that these New Dali people's children go to are not local traditional public schools with local people, but are western-style, micro private schools with few local people. For instance, Mao Mao Guo Er, are led by western popular psychology theory and they provide project-based learning [83]. Operators and their children live in their own social communities with low local attachment, these operators are not so keen on protecting Erhai Lake.

(2) The operators perceived less direct benefits that they had gained, and a lack of ability to connect to PES. The inn operators' capabilities are limited, including their strategic, financial, and 
management. Large and medium-sized enterprises can form expert teams, and are significantly more sophisticated than individual inn operators in terms of policy background and professional knowledge. They can understand PES relative to the overall strategy of the company and corporate social responsibility, and clearly know that PES is important for the development of their enterprises. As a result, there is a stronger WTP for intrinsic compensation and the overall willingness to participate is stronger. Enterprises with a large scale and strong capital are more willing to participate in PES [83]. However, inn operators are different from large and medium-sized enterprise managers. The inn is a small micro-enterprise, and the whole team for an inn generally does not exceed five (investors tend to be 1-2 persons, management team tend to be 2-3 individuals). Such a management team consists mostly of young adults without professional training; only about $40 \%$ of them have received undergraduate education. These operators are limited by their own intrinsic cognitive levels, and consequently the PES payment willingness expression does not reflect rational business behavior and team decision-making behavior; instead it is personal emotional expression.

Excessively high commercial risks exceeding their abilities and the high cost of protection fees for inn construction may disrupt the intrinsic link between the perceived interests and the WTP. Many inns are funded and built with personal loans and other methods, and the amount of investment is relatively large. Some inns need to invest up to tens of millions of CNY and owners are eager to recover costs in the short term. Given the special land ownership system in China, the leases of the farmhouse tended to be mostly 20 years. Therefore, investors bear a great deal of risk. During operation, inns are faced with the cost of wages, rent, etc., as well as the intensified market competition and other uncertainties. Rents of farm houses have risen ten times in five years in some places.

According to ELRPF, an inn with 10 lake-view rooms will pay an annual protection fee of 240,000 CNY, accounting for about $10 \%$ of operating income. Moreover, ELRPF policy designers did not consider other factors such as the room occupancy rates and price fluctuations, consequently increased economic risks fell completely on inn operators. The majority of the operators surveyed stated that the proposed standards imposed by the government had exceeded their financial ability to pay. Of the operators surveyed, $33 \%$ said that they could not afford it. Most operators are willing to pay $1-3 \%$ of their operating income, which is far lower than the existing proposed standards of about $10 \%$.

In the survey, about $40 \%$ of respondents were undergraduate degree holders; thus it is difficult for many to recognize the intrinsic nature of ELRPF. Most operators have very limited knowledge of the relationship among the received benefit, ecosystem services and PES. Only $5 \%$ expressed full understanding of the relationship, while $28 \%$ of the respondents said that they had never heard of it. The different level of understanding and different views of perceived benefits inevitably will make it difficult for the inn operators to accept resource protection fees, thus affecting their WTP.

Local operators are less willing to pay PES payments; this situation is in contrast to findings in other studies where local residents make larger payments [84]. That local operators tend to have low capacities low competition with foreign operators (outside Dali), may be a main factor in this study. From previous analysis (Table 12), the level of education is an important factor affecting the WTP for PES. Most of the local operators are peasants with a relatively low level of education. $20 \%$ of them have completed undergraduate studies, while the rate of foreign operators is $53 \%$. Non-local operators tend to have large capital investment, while most local operators only operated the inn using only their own available funds, limiting their capacity for capital investment. In terms of management performance, foreign operators already exhibit some characteristics of corporate organization, while the local operators still use the family as the business unit. The profitability of local operators may be less than foreign operators which might affect the willingness of local operators to pay. 
Table 12. Analysis of the willingness to pay (WTP) of different groups.

\begin{tabular}{|c|c|c|c|c|c|c|c|c|c|}
\hline \multirow{2}{*}{$\begin{array}{l}\text { Household } \\
\text { Registration }\end{array}$} & \multirow[b]{2}{*}{ Education } & \multirow[b]{2}{*}{ Numbers } & \multirow[b]{2}{*}{ WTP } & \multicolumn{6}{|c|}{ Ratio of Agree (\%) } \\
\hline & & & & $\begin{array}{l}\text { Strongly } \\
\text { Agree }\end{array}$ & Agree & $\begin{array}{l}\text { Agree When } \\
\text { Reasonable }\end{array}$ & Disagree & $\begin{array}{l}\text { Strongly } \\
\text { Disagree }\end{array}$ & Sum \\
\hline \multirow{3}{*}{ Local people } & $\begin{array}{l}\text { Less than high } \\
\text { school }\end{array}$ & 35 & 2.9143 & 0.0 & 40.0 & 31.4 & 25.7 & 2.9 & 100.0 \\
\hline & High school & 62 & 2.4677 & 3.2 & 53.2 & 37.1 & 6.5 & 0.0 & 100.0 \\
\hline & Bachelor & 25 & 3.0400 & 4.0 & 32.0 & 28.0 & 28.0 & 8.0 & 100.0 \\
\hline \multirow{4}{*}{$\begin{array}{l}\text { Non-local } \\
\text { people }\end{array}$} & $\begin{array}{l}\text { Less than high } \\
\text { school }\end{array}$ & 8 & 2.5000 & 12.5 & 37.5 & 37.5 & 12.5 & 0.0 & 100.0 \\
\hline & High school & 78 & 3.0000 & 3.8 & 23.1 & 47.4 & 20.5 & 5.1 & 100.0 \\
\hline & Bachelor & 91 & 3.2857 & 2.2 & 24.2 & 34.1 & 22.0 & 17.6 & 100.0 \\
\hline & Graduate & 8 & 3.0000 & 0.0 & 25.0 & 50.0 & 25.0 & 0.0 & 100.0 \\
\hline
\end{tabular}

During the investigation, many local operators stated that they had lived around Erhai Lake for generations and made a living from it (fishing or farming around the lake). Foreign operators at Erhai Lake have taken local people's resources and land. In addition, the larger inns operated by foreign inn operators result in greater lake pollution. With their higher prices, the foreign operators can enjoy greater profits; thus, in the local inn operators' eyes they should take more responsibility for Erhai Lake. These illustrate the ability of local people to influence their mentality.

(3) The operator is the broker of ecosystem services without professional education, and PES can link the tourist's enjoyment and loss of local residents, that is understandable and a common way. However, in order to reduce the difficulty of the local government, the ELRPF system had been increased for operators as the broker of ecosystem services (Figure 5). Due to the addition of new stakeholders to the PES system, the complex eco-economic relationship of ELRPF is more difficult to be acknowledged and be accepted by public widely.

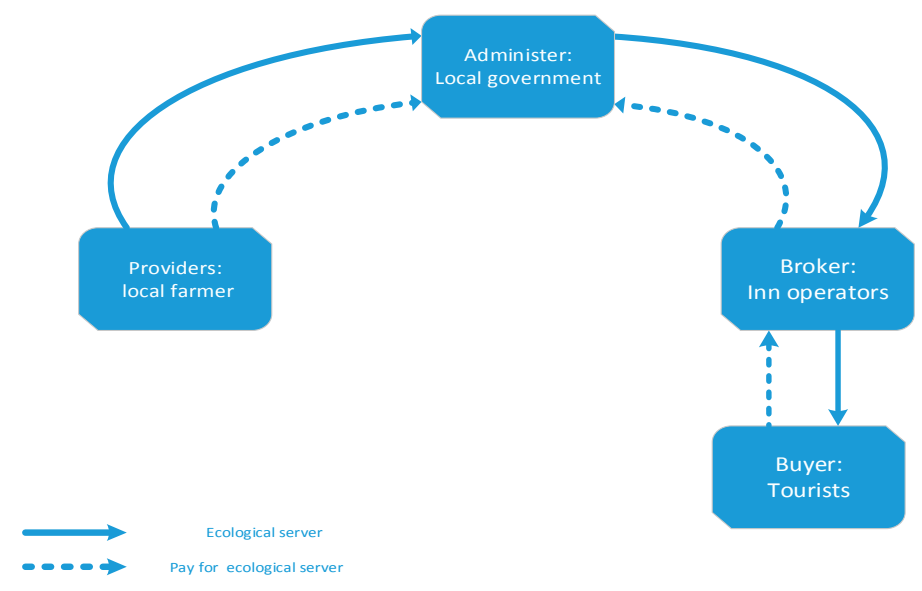

Figure 5. Relationship of stakeholders in ELRPF.

The ELRPF has transformed the causal relationship between the operators' economic benefits, the local residents' loss, the tourists' experience, and the government's responsibility into simple economic relationships, while obscuring the direct correspondence between ecosystem services and economic compensation of PES system. This result may affect inn operators' perceptions of perceived benefits, seriously affecting the willingness of inn operators to pay for PES.

The operators' perceived benefits provided by Erhai Lake ecosystem services are far less understandable and measurable than that from water utilities [1]. Most of operators agreed that the lake does bring them material and immaterial benefits; $65 \%$ of the respondents thought that the lake's landscape has increased their room rates by more than $50 \%$, and $70 \%$ of the respondents said that they enjoy the local natural environment. However, the generation of perceived benefits has certain preconditions, ecosystem components, and scientific principles, and most operators do not recognize the characteristics of ecosystem services and Hedonic price. 
The ELRPF did not explain clearly how to use the funds obtained, further aggravating operator's comprehension of the ELRPF. The operators worried that may be used by local government for other purposes instead of conserving Erhai Lake, which may also affect their WTP, and 37\% of the respondents said that the main reason of unwilling to pay the fee was that they did not believe that the government could reasonably use it. Some operators believed that operating income is the result of their own investments and operations, and they had fulfilled their responsibilities by paying various taxes and fees, and protection of Erhai Lake should be the government's responsibility. In addition, these inn operators encountered various irregularities from the local government during the management process during the construction and operation of inns, which also exacerbated the operator's aversion to the introduction of the policy and further affected WTP.

Most operators believed that inn operation is either an individual lifestyle choice or involves speculation with rising room rates. Erhai Lake's ecosystem services tend to be ignored because the conditions that generate them are complex, indirect, non-consumptive and difficult to measure or characterize. In the survey, about $40 \%$ of respondents were undergraduate students or above; thus, it is difficult for many to recognize the intrinsic nature of ELRPF. Most operators have very limited knowledge of the relationship among the received benefit, ecosystem services and PES. Only $5 \%$ expressed full understanding of the relationship, while $28 \%$ of the respondents said that they had never heard of it. The different level of understanding, and different views of perceived benefits, inevitably will make it difficult for the inn operators to accept resource protection fees, thus affecting their WTP.

\subsection{Policy Implications}

The results of this study have shown that perceived benefit is not a core factor in the formulation of PES systems for inn operators. To make a PES policy widely supported and effective, it is necessary to make use of the characteristics and beneficiaries of ecosystem services and to take targeted measures. Two major results of these findings need to be considered:

(1) The components of the PES system should be simple, and the policy design should reflect the direct relationship of PES. In the ELRPF, fees shall be levied on the economic benefits obtained by the operators, but not collected from tourists who gained ecosystem services, making the operators the direct payer of ecosystem services. This approach may stem from the policy designers' concern that charging fees directly to tourists for water protection may have a negative financial impact on tourists and reduce the number of tourists coming to Dali. Such a thing happened when Lijiang in Yunnan and Fenghuang in Hunan, which are two famous ancient towns, tried to levy protection fees from tourists, causing great controversy among tourists. Moreover, the large number of tourists might lead to a high cost of the collection of ELRPF from them.

Collecting PES from tourists may reduce conflicts. In fact, if ELRPF is directly charged to tourists instead of operators, then the supply and demand relationship between users and providers of ecosystem services will be clarified. For example, if the resource protection fee (ecosystem service) is superimposed on the room rate price (accommodation service), the levy scheme may be relatively easy to implement. With this approach, the perceived benefits, hedonic price, value of ecosystem services to tourists are more direct and logical. The causal relationship between ecoservice acquisition and economic expenditure would be clear, and fee levy would be relatively easy to achieve. Moreover, the payment of PES by tourists is a subjective response based on experience and aesthetics, and there is no problem of operating costs and risks.

(2) Payment for ecosystem services is difficult for the broker of ecosystem services voluntarily. Other types of PES, related to the use of water resources is directly utilized and tourism in national parks, the relation of between ecosystem services and economic income are clear. The utilization of water resources of a basin, protection is in the upper, uses is in the lower, the relationship is clear and direct $[1,85]$. In some national parks, the numbers of franchise tourism bunnies operations, there are management measures such as access control systems. Under such conditions, there are only a few 
buyers and providers of ecosystem services, and PES can be resolved through negotiations and other market methods.

Compared with other PES systems, there are not two kinds of stakeholders in the ELRPF, but three stakeholders. Famers are the provider, and tourists are the buyers, and operators are the brokers of ecosystem services at Erhai Lake. For brokers their goal is to maximize profits, they will try their best to achieve the lowest cost and the most spread. It is very difficult for them to voluntarily pay PES, and the PES policy is also achieved hardly through a market approach.

At Erhai Lake the number of small-scale inns is numerous, the amount of providers, buyers, and brokers of ecosystem services is also huge, and they are intertwined there. There is a possibility that some operators might take "free rides." During construction and operation periods, some inns' construction waste and sewage has been discharged secretly into the lake. For the use of landscape resources in open land, and with a huge number of stakeholders, a PES system is not simple, and PES must be enforced by the government.

\section{Conclusions}

In this study, we seized the opportunity that the government was designing the ELRPF. We carried out research on operators aimed at obtaining information for improving WTP of small tourism operators for a PES. Clearing characteristics of the brokers of ecosystem services is a new role of PES systems.

The operators are dependent on natural resources resulting in certain economic and lifestyle benefits so they should be responsible for PES and Erhai Lake sustainability. However, perceived benefits of operators do not have a significant influence on their WTP for ELRPF. When tourists and local residents get more perceived benefits, they have strong willingness toward PES. Their willingness is affected by their personal emotion, and this is a rational self-interested action. However, operators are small and micro-business owners and face the pressures of survival and development, hence they have few emotional factors toward PES. Their WTP on PES is by perceived benefits received, and this is a rational self-interested action [86]. They are the broker of ecosystem services, whereas PES with no broker between the buyers and the sellers tend to be more successful [87]. Compared with large and medium-sized enterprises, operators do not benefit from advantages afforded by multi-person teams and the range of capabilities they would offer. It is an individual decision that they are unwilling toward PES.

The characteristics of operators' WTP based on PES can also reflect the complexity of the tourism micro-enterprises. A large number of studies have shown that interest and lifestyle are important motives for inn operators to start businesses [88-90]. Through the process of operating inns, the unwillingness to make PES expenditures reflects the fact that operators gradually give up the primacy of maintaining their life-enhancing interests and return to the state of more rational, economics-based decision making [91-93]. During the operation process, operators treated the PES expenditures cautiously, reflecting that they gradually left the state of maintaining the vitality of life and gradually returned to the state of the rational economic person. Moreover, operators lack relevant knowledge and skills of national environmental policies, industry characteristics, business operations, etc., and become the main obstacles that further affect the understanding of PES.

This study is a specific case of PES based on WTP, and we hope that other brokers of ecosystem services can be studied further with respect to influencing factors that might be similar or different, thus forming a new research paradigm. Different SEM could be conducted on operators as part of a comparative study to explore further the relationships between perceived benefit, institutional trust, compensation cognition, and attitudes. With this, more scientific and reasonable conclusions could be obtained.

Author Contributions: P.L. designed the research framework and wrote. M.-H.C. designed the research framework and was responsible for organization. Y.Z. collected and analyzed the data. M.B. participated in writing and revision. L.H. participated in writing and revision. 
Funding: This research was funded by China Nature Science Founding, these grants number are 41761111, 41361107, 41661111.

Conflicts of Interest: The authors declare no conflicts of interest.

\section{References}

1. Pagiola, S.; Platais, G. Payments for Environmental Services; Environment Strategy Notes 3; The World Bank: Washington, DC, USA, 2002.

2. Wunder, S. Revisiting the concept of payments for environmental services. Ecol. Econ. 2015, 117, $234-243$. [CrossRef]

3. Wunder, S. Payments for environmental services: Some nuts and bolts. CIFOR Occas. Pap. 2005, 42, 3-4.

4. Vatn, A. An institutional analysis of payments for environmental services. Ecol. Econ. 2010, 69, 1245-1252. [CrossRef]

5. Muradian, R.; Corbera, E.; Pascual, U.; Kosoy, N.; May, P.H. Reconciling theory and practice: An alternative conceptual framework for understanding payments for environmental services. Ecol. Econ. 2010, 69, 1202-1208. [CrossRef]

6. Bennett, E.M.; Peterson, G.D.; Gordon, L.J. Understanding relationships among multiple ecosystem services. Ecol. Lett. 2009, 12, 1394-1404. [CrossRef] [PubMed]

7. Liu, Q.; Dong, Z.Y.; Xu, Y.S. Payment for Ecosystem Services: A Systematic Review Based on the Capital Asset Framework. J. Environ. Econ. 2016, 1, 123-138.

8. Zhang, Y.; Yang, G. On the connotation of tourism eco compensation. Chin. J. Ecol. 2012, 34, 477-482. [CrossRef]

9. Yu, B.; Cai, Y.; Jin, L.; Du, B. Effects on Willingness to Pay for Marine Conservation: Evidence from Zhejiang Province, China. Sustainability 2018, 10, 2298. [CrossRef]

10. Al Mamun, A.; Fazal, S.A.; Ahmad, G.B.; Yaacob, M.R.B.; Mohamad, M. Willingness to Pay for Environmentally Friendly Products among Low-Income Households along Coastal Peninsular Malaysia. Sustainability 2018, 10, 1316. [CrossRef]

11. Ryan, A.M.; Spash, C.L. Is WTP an attitudinal measure? Empirical analysis of the psychological explanation for contingent values. J. Econ. Psychol. 2011, 32, 674-687. [CrossRef]

12. Nielsen-Pincus, M.; Sussman, P.; Bennett, D.E.; Gosnell, H.; Parker, R. The influence of place on the willingness to pay for ecosystem services. Soc. Nat. Resour. 2017, 30, 1423-1441. [CrossRef]

13. Davis, R.K. Recreation planning as an economic problem. Nat. Resour. J. 1963, 3, 239.

14. Wilson, C.; Tisdell, C. Attitudes to Entry Fees to National Parks: Results and Policy Implications From A Queensland Case Study. Econ. Anal. Policy 2004, 34, 79-102. [CrossRef]

15. Bandara, R.; Tisdell, $C$. The net benefit of saving the Asian elephant: A policy and contingent valuation study. Ecol. Econ. 2004, 48, 93-107. [CrossRef]

16. Cranford, M.; Mourato, S. Community conservation and a two-stage approach to payments for ecosystem services. Ecol. Econ. 2011, 71, 89-98. [CrossRef]

17. Togridou, A.; Hovardas, T.; Pantis, J.D. Determinants of visitors' willingness to pay for the National Marine Park of Zakynthos, Greece. Ecol. Econ. 2006, 60, 308-319. [CrossRef]

18. Reynisdottir, M.; Song, H.; Agrusa, J. Willingness to pay entrance fees to natural attractions: An Icelandic case study. Tour. Manag. 2008, 29, 1076-1083. [CrossRef]

19. Batel, A.; Basta, J.; Mackelworth, P. Valuing visitor willingness to pay for marine conservation-The case of the proposed Cres-Lošinj Marine Protected Area, Croatia. Ocean Coast. Manag. 2014, 95, 72-80. [CrossRef]

20. Kontogianni, A.; Damigos, D.; Tourkolias, C.; Vousdoukas, M.; Velegrakis, A.; Zanou, B.; Skourtos, M. Eliciting beach users' willingness to pay for protecting European beaches from beachrock processes. Ocean Coast. Manag. 2014, 98, 167-175. [CrossRef]

21. Brouwer, R.; Brouwer, S.; Eleveld, M.A.; Verbraak, M.; Wagtendonk, A.J.; van der Woerd, H.J. Public willingness to pay for alternative management regimes of remote marine protected areas in the North Sea. Mar. Policy 2016, 68, 195-204. [CrossRef]

22. Mmopelwa, G.; Kgathi, D.L.; Molefhe, L. Tourists' perceptions and their willingness to pay for park fees: A case study of self-drive tourists and clients for mobile tour operators in Moremi Game Reserve, Botswana. Tour. Manag. 2007, 28, 1044-1056. [CrossRef] 
23. Chung, J.Y.; Kyle, G.T.; Petrick, J.F.; Absher, J.D. Fairness of prices, user fee policy and willingness to pay among visitors to a national forest. Tour. Manag. 2011, 32, 1038-1046. [CrossRef]

24. Kamri, T. Willingness to Pay for Conservation of Natural Resources in the Gunung Gading National Park, Sarawak. Procedia Soc. Behav. Sci. 2013, 101, 506-515. [CrossRef]

25. Tyrväinen, L.; Ojala, A.; Korpela, K.; Lanki, T.; Tsunetsugu, Y.; Kagawa, T. The influence of urban green environments on stress relief measures: A field experiment. J. Environ. Psychol. 2014, 38, 1-9. [CrossRef]

26. White, P.; Lovett, J. Public preferences and willingness-to-pay for nature conservation in the North York Moors National Park, UK. J. Environ. Manag. 1999, 55, 1-13. [CrossRef]

27. López-Mosquera, N. Gender differences, theory of planned behavior and willingness to pay. J. Environ. Psychol. 2016, 45, 165-175. [CrossRef]

28. Johnson, G.; Scholes, K.; Whittington, R. Exploring Corporate Strategy: Text \& Cases (8th Edition). Available online: https:/ / www.scirp.org/(S(i43dyn45teexjx455qlt3d2q))/reference/ReferencesPapers.aspx? ReferenceID=1242479 (accessed on 30 October 2018).

29. Ateljevic, J. Small tourism firms and management practices in New Zealand: The Centre Stage Macro Region. Tour. Manag. 2007, 28, 307-316. [CrossRef]

30. Chinese Research Academy of Environmental Sciences (CRAES). 13th Five Year Plan on Water Resources Management and Protection in Erhai Lake Basin; Chinese Research Academy of Environmental Sciences: Beijing, China, 2016.

31. Bureau of Diplomatic Security (DSB). Dali Statistical Yearbook 2015; China Statistics Press: Beijing, China, 2016.

32. Long, X.; Yang, G.H. A comparative study on satisfaction quotient of chinese and foreign visitors about inns of local style in old city of Dali. Hum. Geogr. 2008, 23, 95-100. [CrossRef]

33. Chen, X. Gold collar going back to the village. Southern Weekly, 13 January 2012.

34. Brown, G.M.; Pollakowski, H.O. Economic valuation of shoreline. Rev. Econ. Stat. 1977, 59, $272-278$. [CrossRef]

35. Loomis, J.; Feldman, M. Estimating the benefits of maintaining adequate lake levels to homeowners using the hedonic property method. Water Resour. Res. 2003, 39. [CrossRef]

36. Wang, M.; Liu, X.; Zhang, J. Evaluate method and classification standard on lake eutrophication. Environ. Monit. China 2002, 18, 47-49.

37. He, Y.H. Do not let protection fee be a barrier in Erhai. Beijing Youth Daily, 11 December 2015.

38. Peters, H.; Hawkins, J.P. Access to marine parks: A comparative study in willingness to pay. Ocean Coast. Manag. 2009, 52, 219-228. [CrossRef]

39. Halkos, G.; Matsiori, S. Exploring social attitude and willingness to pay for water resources conservation. J. Behav. Exp. Econ. 2014, 49, 54-62. [CrossRef]

40. López-Mosquera, N.; García, T.; Barrena, R. An extension of the Theory of Planned Behavior to predict willingness to pay for the conservation of an urban park. J. Environ. Manag. 2014, 135, 91-99. [CrossRef] [PubMed]

41. Huang, L.-F.; Chiang, C.-C.; Chen, H.-C. Willingness to pay of visitors for the nature-based public park: An extension of theory of planning behavior (TPB). J. Inf. Optim. Sci. 2014, 35, 405-429. [CrossRef]

42. Kaffashi, S.; Yacob, M.R.; Clark, M.S.; Radam, A.; Mamat, M.F. Exploring visitors' willingness to pay to generate revenues for managing the National Elephant Conservation Center in Malaysia. For. Policy Econ. 2015, 56, 9-19. [CrossRef]

43. Del Saz Salazar, S.; Menendez, L.G. Estimating the non-market benefits of an urban park: Does proximity matter? Land Use Policy 2007, 24, 296-305. [CrossRef]

44. Hayes, M.C.; Peterson, M.N.; Heinen-Kay, J.L.; Langerhans, R.B. Tourism-related drivers of support for protection of fisheries resources on Andros Island, The Bahamas. Ocean Coast. Manag. 2015, 106, 118-123. [CrossRef]

45. Lo, A.Y.; Jim, C. Willingness of residents to pay and motives for conservation of urban green spaces in the compact city of Hong Kong. Urban For. Urban Green. 2010, 9, 113-120. [CrossRef]

46. Song, X.; Lv, X.; Li, C. Willingness and motivation of residents to pay for conservation of urban green spaces in Jinan, China. Acta Ecol. Sin. 2015, 35, 89-94. [CrossRef]

47. Rodríguez-Ortega, T.; Bernués, A.; Alfnes, F. Psychographic profile affects willingness to pay for ecosystem services provided by Mediterranean high nature value farmland. Ecol. Econ. 2016, 128, 232-245. [CrossRef] 
48. López-Mosquera, N.; Sánchez, M. Direct and indirect effects of received benefits and place attachment in willingness to pay and loyalty in suburban natural areas. J. Environ. Psychol. 2013, 34, 27-35. [CrossRef]

49. Castro, A.J.; Martín-López, B.; García-Llorente, M.; Aguilera, P.A.; López, E.; Cabello, J. Social preferences regarding the delivery of ecosystem services in a semiarid Mediterranean region. J. Arid Environ. 2011, 75, 1201-1208. [CrossRef]

50. Chen, W.Y. Public willingness-to-pay for conserving urban heritage trees in Guangzhou, south China. Urban For. Urban Green. 2015, 14, 796-805. [CrossRef]

51. Latinopoulos, D.; Mallios, Z.; Latinopoulos, P. Valuing the benefits of an urban park project: A contingent valuation study in Thessaloniki, Greece. Land Use Policy 2016, 55, 130-141. [CrossRef]

52. Yang, H.; Ling, W.-F.; Duan, P. Residential Guest: An Intermediate between the Host and the Guest: A Study of Dayan, Shuhe of Lijiang, and Shaxi of Dali in the Perspective of Tourism Anthropology. J. Guangxi Univ. Natl. (Philos. Soc. Sci. Ed.) 2012, 34, 44-50.

53. Liu, M.T.C.; Brock, J.L.; Shi, G.C.; Chu, R.; Tseng, T.-H. Perceived benefits, perceived risk, and trust: Influences on consumers' group buying behaviour. Asia Pac. J. Mark. Logist. 2013, 25, 225-248.

54. Mano, H.; Oliver, R.L. Assessing the dimensionality and structure of the consumption experience: Evaluation, feeling, and satisfaction. J. Consum. Res. 1993, 20, 451-466. [CrossRef]

55. Gerpott, T.J.; Paukert, M. Determinants of willingness to pay for smart meters: An empirical analysis of household customers in Germany. Energy Policy 2013, 61, 483-495. [CrossRef]

56. Gao, Y.; Mattila, A.S.; Lee, S. A meta-analysis of behavioral intentions for environment-friendly initiatives in hospitality research. Int. J. Hosp. Manag. 2016, 54, 107-115. [CrossRef]

57. Beierle, T.C. Democracy in Practice: Public Participation in Environmental Decisions; Routledge: New York, NY, USA, 2010.

58. Van Oorschot, W.; Arts, W.; Gelissen, J. Social capital in Europe: Measurement and social and regional distribution of a multifaceted phenomenon. Acta Sociol. 2006, 49, 149-167. [CrossRef]

59. Cvetkovich, G.; Winter, P.L. Trust And Social Representations Of The Management Of Threatened And Endangered Species. Environ. Behav. 2016, 35, 286-307. [CrossRef]

60. Jones, N.; Clark, J.R.; Malesios, C. Social capital and willingness-to-pay for coastal defences in south-east England. Ecol. Econ. 2015, 119, 74-82. [CrossRef]

61. Li, C.-X.; Peng, F.-Q.; Chen, H. Analysis of the influencing factors for willingness to pay of payment for ecosystem services of river basin: A case of Changsha Reach of Xiang Jiang River Basin. Econ. Geogr. 2012, 32, 130-135.

62. Zheng, X.; Bai, T. Willingness to Pay for Eco-compensation and Its Influencing Factors of the Residents in the Cities Getting Drinkable Water from Dahuofang Reservoir. Wetl. Sci. 2016, 1, 65-71.

63. Kostakis, I.; Sardianou, E. Which factors affect the willingness of tourists to pay for renewable energy? Renew. Energy 2012, 38, 169-172. [CrossRef]

64. Kotchen, M.J.; Reiling, S.D. Environmental attitudes, motivations, and contingent valuation of nonuse values: A case study involving endangered species. Ecol. Econ. 2000, 32, 93-107. [CrossRef]

65. Moen, B.-E. Determinants of safety priorities in transport-The effect of personality, worry, optimism, attitudes and willingness to pay. Saf. Sci. 2007, 45, 848-863. [CrossRef]

66. Husted, B.W.; Russo, M.V.; Meza, C.E.B.; Tilleman, S.G. An exploratory study of environmental attitudes and the willingness to pay for environmental certification in Mexico. J. Bus. Res. 2014, 67, 891-899. [CrossRef]

67. Ateljevic, I.; Doorne, S. Tourism as an escape: Long-term travelers in New Zealand. Tour. Anal. 2000, 5, 131-136.

68. Getz, D.; Petersen, T. Growth and profit-oriented entrepreneurship among family business owners in the tourism and hospitality industry. Int. J. Hosp. Manag. 2005, 24, 219-242. [CrossRef]

69. Tew, C.; Barbieri, C. The perceived benefits of agritourism: The provider's perspective. Tour. Manag. 2012, 33, 215-224. [CrossRef]

70. Rosenberger, R.S.; Needham, M.D.; Morzillo, A.T.; Moehrke, C. Attitudes, willingness to pay, and stated values for recreation use fees at an urban proximate forest. J. For. Econ. 2012, 18, 271-281. [CrossRef]

71. Rollins, R.; Trotter, W. Public attitudes regarding user fees in provincial forest lands. Leisure/Loisir 1999, 24, 139-159. [CrossRef]

72. Lin, C.-Y.; Syrgabayeva, D. Mechanism of environmental concern on intention to pay more for renewable energy: Application to a developing country. Asia Pac. Manag. Rev. 2016, 21, 125-134. [CrossRef] 
73. Shiau, W. Introduction and Application of Statistical Analysis: SPSS in Chinese Version+ PLS-SEM (SmartPLS); GOTOP Information Inc.: Taipei, Taiwan, 2013.

74. Reinartz, W.; Haenlein, M.; Henseler, J. An empirical comparison of the efficacy of covariance-based and variance-based SEM. Int. J. Res. Mark. 2009, 26, 332-344. [CrossRef]

75. Fornell, C.; Larcker, D.F. Structural equation models with unobservable variables and measurement error: Algebra and statistics. J. Mark. Res. 1981, 18, 382-388. [CrossRef]

76. Chin, W.W. The partial least squares approach to structural equation modeling. Mod. Methods Bus. Res. 1998, 295, 295-336.

77. Henseler, J.; Ringle, C.M.; Sarstedt, M. A new criterion for assessing discriminant validity in variance-based structural equation modeling. J. Acad. Mark. Sci. 2015, 43, 115-135. [CrossRef]

78. John, O.P.; Benet-Martinez, V. Measurement: Reliability, construct validation, and scale construction. In Handbook of Research Methods in Social and Personality Psychology; Cambridge University Press: Cambridge, UK, 2000.

79. Hair, J.F.; Sarstedt, M.; Ringle, C.M.; Mena, J.A. An assessment of the use of partial least squares structural equation modeling in marketing research. J. Acad. Mark. Sci. 2012, 40, 414-433. [CrossRef]

80. Hair, J.F., Jr.; Hult, G.T.M.; Ringle, C.; Sarstedt, M. A Primer on Partial Least Squares Structural Equation Modeling (PLS-SEM); Sage Publications: London, UK, 2016.

81. Kelley, C.L.; Marquette, R.P. A tax primer for bed and breakfasts. Cornell Hotel Restaur. Admin. Q. 1996, 37, $34-42$.

82. Qi, S.N.H.; Duan, M.; Zhang, F. Empirical analysis of Tianjin small and medium-sized enterprises' willingness to participate in pes. Water Resour. Prot. 2016, 4, 147-153.

83. Zuo, M. How China's Western-style micro schools seek to free kids from the stresses of traditional education. South China Morning Post, 8 December 2017.

84. Yadav, L.P.; O'Neill, S. Is there agreement between beneficiaries on who should bear the costs of conserving farm landscapes? Tour. Manag. 2013, 39, 62-70. [CrossRef]

85. Dixon, J.; Xie, J. Promoting Market-Oriented Ecological Compensation Mechanisms: Payment for Ecosystem Services in China; World Bank: Washington, DC, USA, 2009.

86. Daly, H.E.; Farley, J. Ecological Economics: Principles and Applications, 2nd ed.; Island Press: Washington, DC, USA, 2011.

87. Grima, N.; Singh, S.J.; Smetschka, B.; Ringhofer, L. Payment for Ecosystem Services (PES) in Latin America: Analysing the performance of 40 case studies. Ecosyst. Serv. 2016, 17, 24-32. [CrossRef]

88. Getz, D.; Carlsen, J. Characteristics and goals of family and owner-operated businesses in the rural tourism and hospitality sectors. Tour. Manag. 2000, 21, 547-560. [CrossRef]

89. Gilmore, A.; Carson, D.; O'Donnell, A. Small business owner-managers and their attitude to risk. Mark. Intell. Plan. 2004, 22, 349-360. [CrossRef]

90. Nilsson, P.Å.; Petersen, T.; Wanhill, S. Public support for tourism SMEs in peripheral areas: The arjeplog project, northern Sweden. Serv. Ind. J. 2005, 25, 579-599. [CrossRef]

91. Williams, A.M.; Shaw, G.; Greenwood, J. From tourist to tourism entrepreneur, from consumption to production: Evidence from Cornwall, England. Environ. Plan. A 1989, 21, 1639-1653. [CrossRef]

92. Sundbo, J.; Orfila-Sintes, F.; Sørensen, F. The innovative behaviour of tourism firms-Comparative studies of Denmark and Spain. Res. Policy 2007, 36, 88-106. [CrossRef]

93. Jaafar, M.; Abdul-Aziz, A.R.; Maideen, S.A.; Mohd, S.Z. Entrepreneurship in the tourism industry: Issues in developing countries. Int. J. Hosp. Manag. 2011, 30, 827-835. [CrossRef]

(C) 2018 by the authors. Licensee MDPI, Basel, Switzerland. This article is an open access article distributed under the terms and conditions of the Creative Commons Attribution (CC BY) license (http:// creativecommons.org/licenses/by/4.0/). 